\title{
Microstructural Stability of Ti based Composites Fabricated by Spark Plasma Sintering
}

\author{
${ }^{1}$ Yoshimi Watanabe, ${ }^{1}$ Miwa Hattori, ${ }^{1}$ Tadachika Chiba, ${ }^{1}$ Hisashi Sato \\ ${ }^{1}$ Nagoya Institute of Technology, Japan
}

In our previous study, the effects of $\mathrm{TiC}$ heterogeneous nucleation site particles on formability and microstructure of additive manufactured (AMed) Ti-6Al-4V products were studied. It was found that the addition of $\mathrm{TiC}$ particles decreased the grain size of primary $\beta$ phase in AMed Ti-6Al-4V samples, since TiC particles act as heterogeneous nucleation sites. It is also found that the density of AMed Ti-6Al-4V samples could be increased by addition of TiC particles. It is expected that solid-state $\beta$-grain growth by the high temperature thermal cycles associated with layer-by-layer manufacturing can be suppressed by the pinning effect of $\mathrm{TiC}$ heterogeneous nucleation site particles. In this study, the pinning effect of heterogeneous nucleation site particles on microstructure of $\mathrm{Ti}$ at elevated temperatures is studied. For this purpose, Ti$0.3 \mathrm{vol} \% \mathrm{TiC}$ samples fabricated by spark plasma sintering (SPS) are used as the model materials, and microstructure and hardness of the samples heat treated at elevated temperatures are studied.

\section{Introduction}

Additive manufacturing (AM), which is commonly called 3D printing, is the process of fabricating objects layer by layer from 3D numerical models, as opposed to traditional subtractive manufacturing technologies. Compared to traditional manufacturing technologies, the most significant advantage of AM is its freeform fabrication capability of complex parts directly from feedstock materials without involving traditional manufacturing technologies to achieve desired shapes ${ }^{1-3)}$. Ti-6Al-4V has been widely used in aerospace, petrochemical, biomedical and other fields because of its low density, high specific strength, excellent corrosion resistance and good welding performance. This alloy has been well studied in the field of AM. Because of the rapid cooling rates and directional solidification, the AMed Ti-6Al-4V products have microstructures, and 3D multiscale architectures that differ from their cast and wrought counterparts ${ }^{3-6)}$. For example, the local solidification of small melt pools during AM can result in epitaxial growth and the formation of elongated columnar grains as heat is primarily extracted through the previously manufactured (solidified) layer, often across a steep thermal gradient, as shown in Fig. 1 (a) ${ }^{7}$ ). In addition, the high temperature thermal cycles associated with layer-by-layer manufacturing promote solid-state $\beta$-grain growth.

It is well known that equiaxed and fine grain structures are promoted during heterogeneous solidification with heterogeneous nucleation site particles ${ }^{8-10)}$. Therefore, it is expected that the microstructure and mechanical properties of AMed Ti-6Al-4V products can be improved by addition of heterogeneous nucleation site particles in powder for AM. In our previous study, the effects of heterogeneous nucleation site particles on formability and microstructure of AMed Ti-6Al$4 \mathrm{~V}$ products were studied ${ }^{7}$. In that study, TiC particles are used as heterogeneous nucleation site particles, since lattice matching between Ti-6Al-4V and TiC is good. Figure 1 (b) shows the microstructural evolution during AM of Ti-6Al-4V using proposed powder with TiC heterogeneous nucleation site particles ${ }^{7}$. Equiaxed and fine grain structures are formed by the heterogeneous solidification with heterogeneous nucleation site particles. Moreover, solid-state $\beta$-grain growth by the high temperature thermal cycles associated with layer-by-layer manufacturing maybe suppressed by the pinning effect of heterogeneous nucleation site particles.

In this study, the pinning effect of heterogeneous nucleation site particles on microstructure of $\mathrm{Ti}$ at elevated temperatures is studied. For this purpose, Ti-0.3vol\%TiC samples fabricated by spark plasma sintering (SPS) are used as the model materials, and microstructure and hardness of the samples heat treated at elevated temperatures are studied.

\section{Experimental Procedure}

TiC particles (Kojundo Chemical Laboratory Co., Ltd., $2-5 \mu \mathrm{m}$ ) were mixed with pure Ti particles (Kojundo Chemical Laboratory Co., Ltd., $45 \mu \mathrm{m}$ ), where the volume fraction of TiC particles was fixed to be $0.3 \mathrm{vol} \%$. The mixed powder was sintered by SPS apparatus (SPS Syntax SPS-515S) at $800^{\circ} \mathrm{C}$ for 10 min under an applied stress of $45 \mathrm{MPa}$.

SPSed specimens were cut into small samples, and heat treatment of the samples was then performed at $800{ }^{\circ} \mathrm{C}, 900{ }^{\circ} \mathrm{C}$ and $1000^{\circ} \mathrm{C}$ for $30 \mathrm{~min}$ or $120 \mathrm{~min}$ in an evacuated quartz capsule. Microstructural evolution by heat treatment was studied by optical microscopy $(\mathrm{OM})$ after polishing and electrical etching. The mean grain size was calculated using a mean linear intercept technique. For evaluating mechanical property, micro-Vickers hardness $(H V)$ indentation tests were carried out for all samples at room temperature (RT) at $4.9 \mathrm{~N}$ for $15 \mathrm{~s}$. The hardness at each sample was measured 5 times and the average was obtained. Flow diagram of experimental procedure is summarized as shown in Fig. 2. 


\section{Results and Discussion}

The OM microstructures of SPSed Ti sample and Ti-0.3vol\%TiC sample before the heat treatment are shown in Fig. 3 (a) and (b), respectively. It is seen from these figures that the bulk-shaped Ti sample and Ti- 0.3 vol\% $\%$ iC sample are successfully fabricated by the SPS method. Average grain size of Ti sample and Ti-0.3vol\%TiC sample before the heat treatment are $9.6 \mu \mathrm{m}$ and $6.7 \mu \mathrm{m}$, respectively. Smaller grain size is found for Ti-0.3vol\% TiC sample, since the grain growth during the SPS method can be inhibited in the presence of TiC particles. Therefore, it is expected that the TiC heterogeneous nucleation site particles show the pinning effect, and grain growth by the heating can be suppressed.

Heat treatment at $800{ }^{\circ} \mathrm{C}$ is carried out for both Ti samples sintered with and without $0.3 \mathrm{vol} \%$ TiC particles. Figures 4 (a) and (b) are $\mathrm{OM}$ microstructures of Ti sample and $\mathrm{Ti}-0.3 \mathrm{vol} \% \mathrm{TiC}$ sample heat treated at $800{ }^{\circ} \mathrm{C}$ for $30 \mathrm{~min}$, respectively, while Figures 4 (c) and (d) are those heat treated at $800{ }^{\circ} \mathrm{C}$ for $120 \mathrm{~min}$, respectively. One can see that the grain growth by heating can be observed. It is also found that the grain growth can be inhibited in the presence of second phase particles which pin grain boundaries in place.

The OM microstructures of heat treated Ti samples without and with 0.3 vol\% TiC particles are shown in Figs. 5 (a-b) and (c-d), respectively. In Fig. 6, the microstructures of the Ti samples and $\mathrm{TiC}-0.3 \mathrm{vol} \% \mathrm{TiC}$ samples heat treated at $1000{ }^{\circ} \mathrm{C}$ are compared. The grain structure becomes coarser with increased heating temperature. Notable differences observed in Figs. 5 and 6 are relatively smaller grain found in the Ti- $0.3 \mathrm{vol} \% \mathrm{TiC}$ samples.

A quantitative analysis of the average grain size of the Ti samples and Ti- $0.3 \mathrm{vol} \% \mathrm{TiC}$ samples before and after the heat treatment is carried out, and the results are shown in Fig. 7. The broken lines in Fig. 7 show the average grain size of the samples before the heat treatment. It is seen that the grain size is increased with increased heating temperature. Comparing the results shows that the addition of TiC particles achieves an average grain size reduction of $30 \%$ for the un-heated sample and $26 \%$ to $43 \%$ for the heated samples. Smaller grain found in the Ti- $0.3 \mathrm{vol} \% \mathrm{TiC}$ samples can be explained by the pinning effect by the TiC particles.

Figure 8 shows the micro-Vickers hardness of each sample. The broken lines in Fig. 8 show the hardness of the samples before the heat treatment. The un-heated $\mathrm{TiC}-0.3 \mathrm{vol} \% \mathrm{TiC}$ sample showed higher hardness than un-heated Ti sample, as expected. Thus, the TiC heterogeneous nucleation site particles act as the dispersion particles. It is observed generally in Fig. 8 that the hardness of heated samples are better for the un-heated samples. This cannot be explained by the grain structures shown in Figs. 3 to 7, which show the heated samples have coarse grain structure. Four different hardening mechanisms exist in metallic materials and are present in $\mathrm{Ti}$ alloys: solid solution hardening (the interstitial elements $\mathrm{O}$ and $\mathrm{N}$ are especially important), dislocation hardening, boundary hardening, and precipitation hardening ${ }^{11)}$. According to the binary phase diagram of Ti-C shown in Fig. $9^{12}$, there are solid solution of $\alpha \mathrm{Ti}$ and $\beta \mathrm{Ti}$. On other word, TiC dissolves into Ti by heat treatment. Therefore, the effect seems to result from a solid solution hardening, but has to be verified by further experiments in the future.

\section{Conclusions}

In this study, the pinning effects of heterogeneous nucleation site particles on microstructure of Ti at elevated temperatures are studied. For this purpose, Ti sample and Ti-0.3vol\% TiC samples are fabricated by spark plasma sintering (SPS), and microstructure and hardness of the samples heat treated at elevated temperatures are studied. Important findings in this study are listed as follows:

1) It is found that the grain structure becomes coarser with increased heating temperature. It is also found that the grain growth can be inhibited in the presence of second phase particles which pin grain boundaries in place.

2) The $\mathrm{TiC}$ heterogeneous nucleation site particles act as the dispersion particles.

3) The hardness of heated samples are found to be better for the un-heated samples. This phenomenon can be explained by the solid solution hardening cause by TiC dissolution during heating.

\section{Acknowledgments}

This research work was supported by the Japan Science and Technology Agency (JST) under Industry-Academia Collaborative R\&D Program "Heterogeneous Structure Control: Towards Innovative Development of Metallic Structural Materials".

\section{References}

[1] W.E. Frazier, J. Mater. Eng. Perform. 23 (2014) 1917-1928.

[2] D. Herzog, V. Seyda, E. Wycisk and C. Emmelmann, Acta Mater. 117 (2016) 371-392.

[3] S. Liu and Y. C. Shin, Mater. Des. 164 (2019) 107552 1-23.

[4] P.A. Kobryn and S.L. Semiatin, JOM 53 (2001) 40-42. 
[5] I. Yadroitsev, P. Krakhmalev and I. Yadroitsava, J. Alloys Comp. 583 (2014) 404-409.

[6] F. Zhechao and F. Hongwei, Results Phys. 10 (2018) 660-664.

[7] Y. Watanabe, M. Sato, T. Chiba, H. Sato, N. Sato and S. Nakano, Metal. Mater. Trans. A, 51 (2020) 1345-1352.

[8] A. Kamio, J. Jpn Foundry Eng. Soc. 68 (1996) 1075-1083.

[9] Y. Watanabe, T. Hamada and H. Sato, Jpn J. Appl. Phys. 55 (2016) 01AG01 (10 pages).

[10]Y. Watanabe, R. Yamazaki, K. Yamanaka and H. Sato, J. Mater. Proc. Tech. 255 (2018) 400-410.

[11] E. Brandl, A. Schoberth and C. Leyens, Mater. Sci. Eng. A 532 (2012) 295-307.

[12] T. B. Massalski, Editor-in-Chief: Binary Alloy Phase Diagrams, Second Edition Plus Updates on CD-ROM Version 1.0, ASM International, Materials Park, OH, (1996).
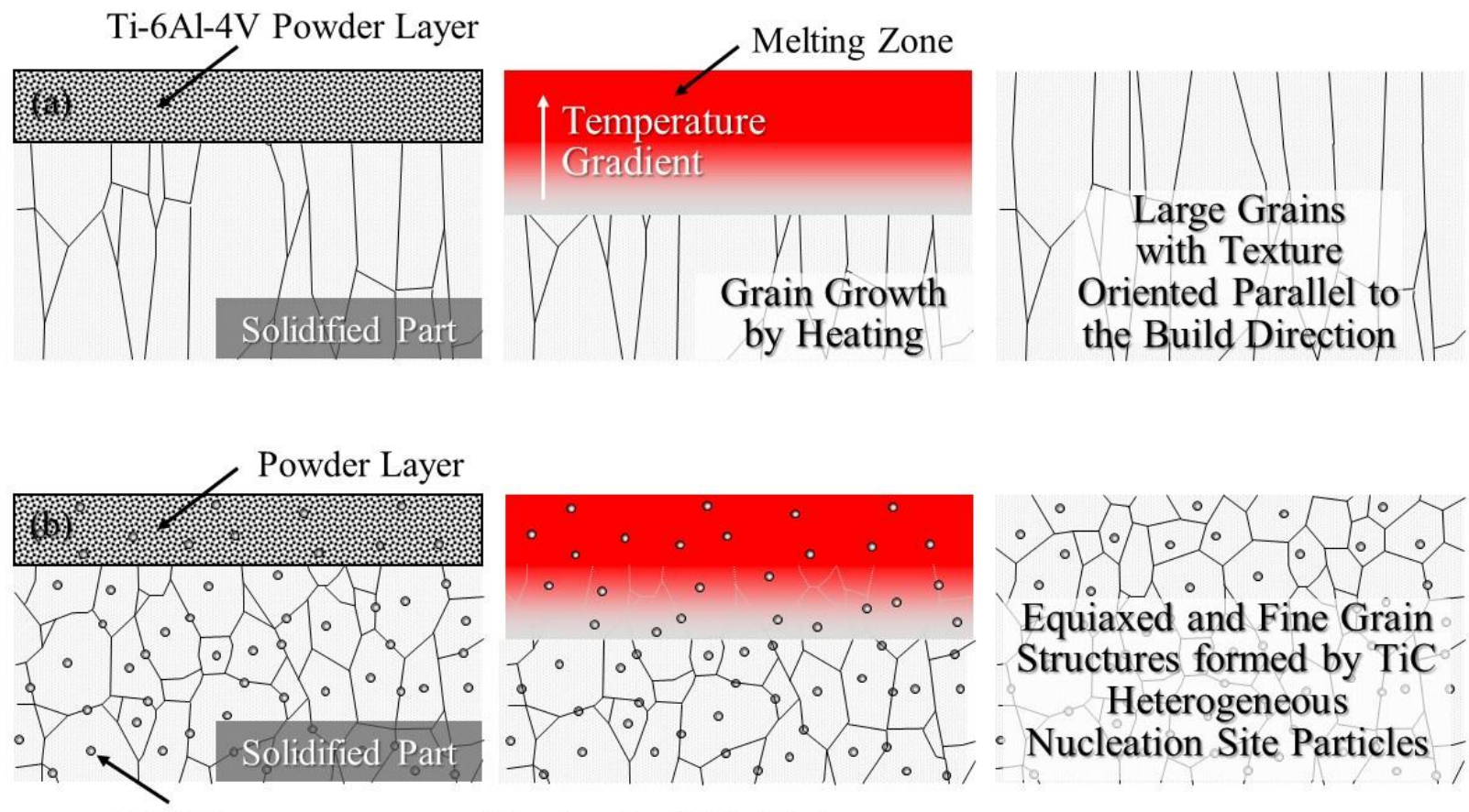

TiC Heterogeneous
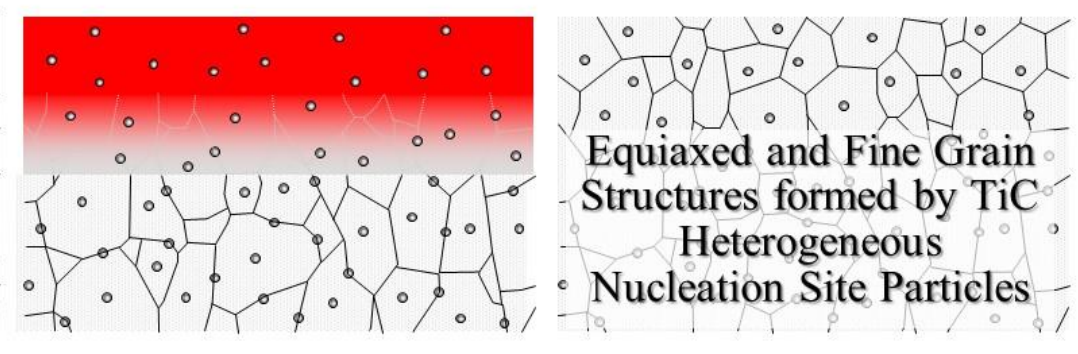

Nucleation Site Particles

\section{Pinning by $\mathrm{TiC}$ Heterogeneous \\ Nucleation Site Particles}

Fig. 1 Microstructural evolution during AM using (a) conventional metallic powder and (b) proposed powder with heterogeneous nucleation site particles. ${ }^{7)}$ 


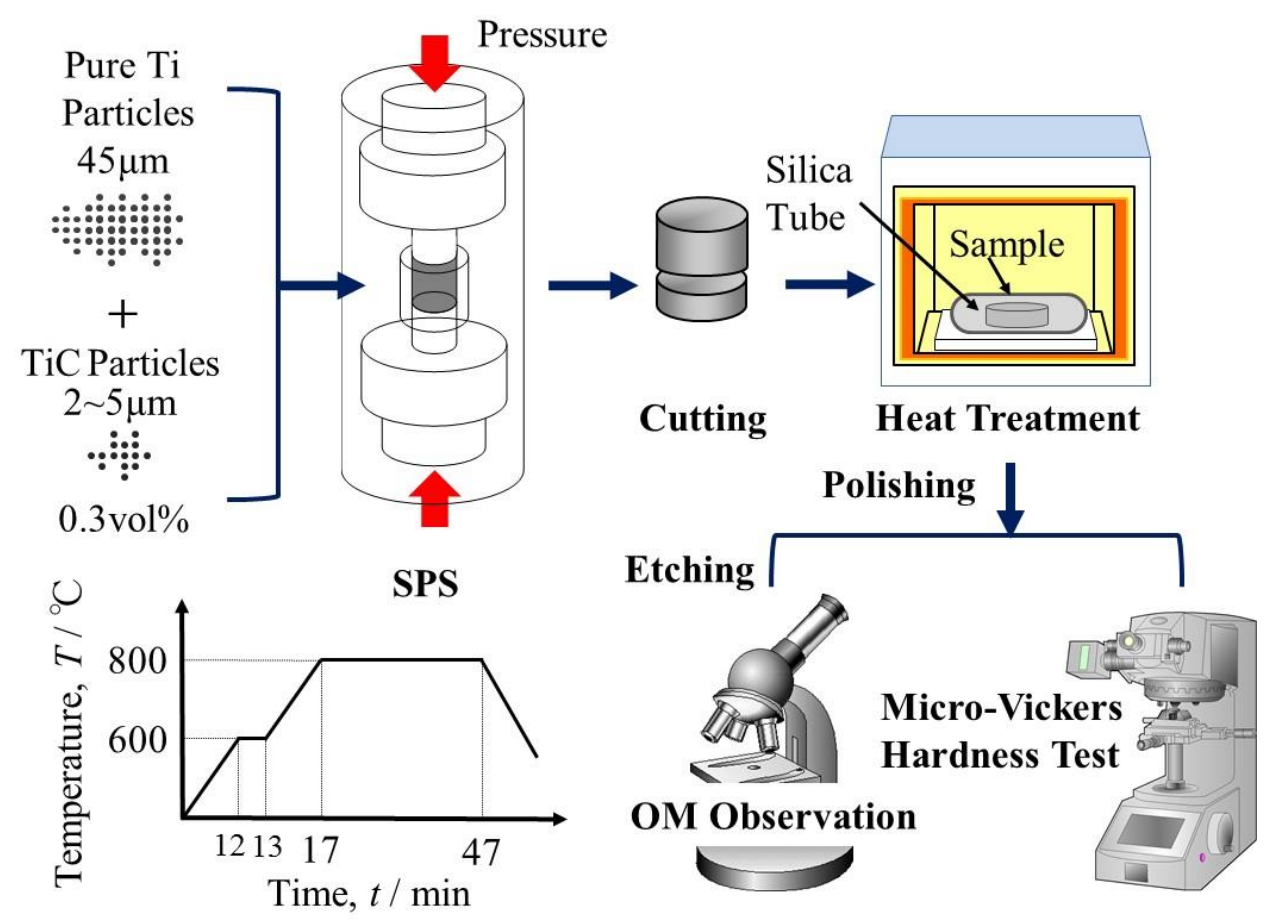

Fig. 2 Flow diagram of experiment procedure.
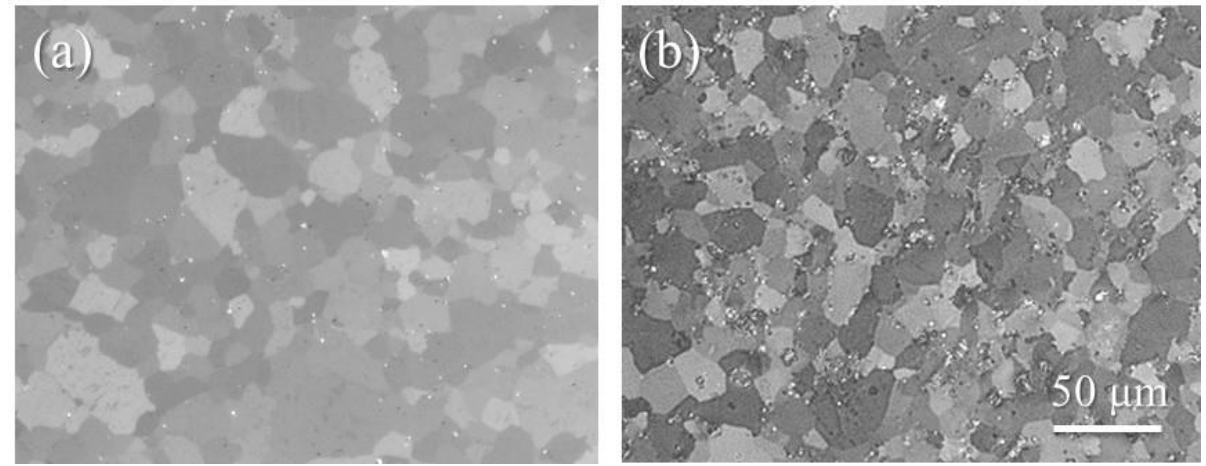

Fig. 3 OM photomicrographs showing (a) Ti and (b) Ti-0.3vol\% TiC samples before the heat treatment.
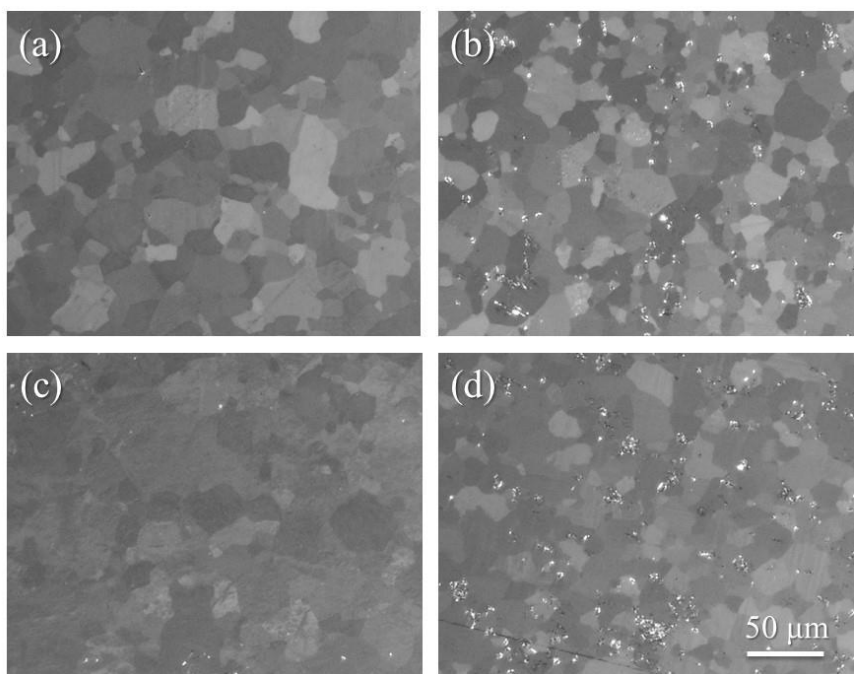

Fig. $4 \mathrm{OM}$ microstructures of (a) Ti sample heat treated at $800{ }^{\circ} \mathrm{C}$ for $30 \mathrm{~min}$, (b) Ti-0.3vol\% TiC sample heat treated at $800{ }^{\circ} \mathrm{C}$ for 30 min, (c) Ti sample heat treated at $800^{\circ} \mathrm{C}$ for $120 \mathrm{~min}$, and (d) Ti- $0.3 \mathrm{vol} \% \mathrm{TiC}$ sample heat treated at $800{ }^{\circ} \mathrm{C}$ for $120 \mathrm{~min}$. 

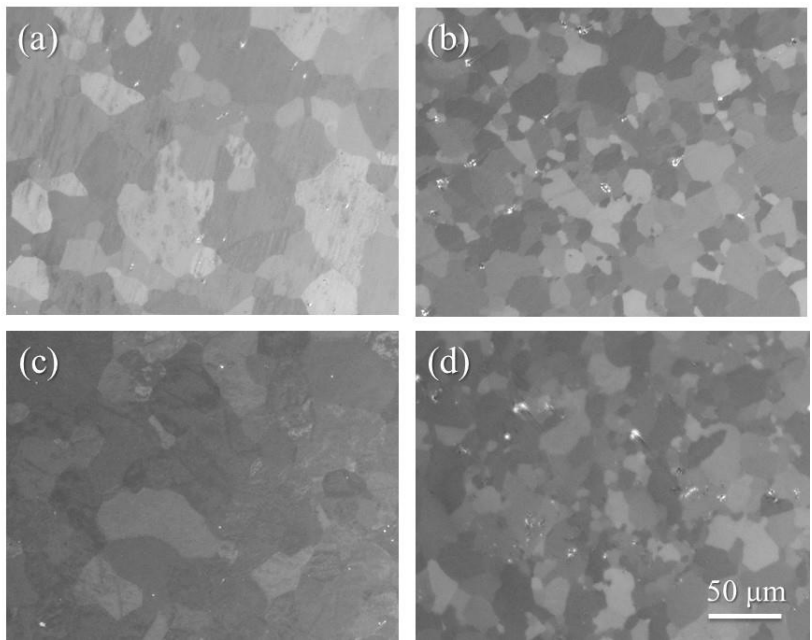

Fig. $5 \mathrm{OM}$ microstructures of (a) Ti sample heat treated at $900{ }^{\circ} \mathrm{C}$ for $30 \mathrm{~min}$, (b) Ti-0.3vol\% TiC sample heat treated at $900{ }^{\circ} \mathrm{C}$ for 30 min, (c) Ti sample heat treated at $900{ }^{\circ} \mathrm{C}$ for $120 \mathrm{~min}$, and (d) Ti- $0.3 \mathrm{vol} \% \mathrm{TiC}$ sample heat treated at $900{ }^{\circ} \mathrm{C}$ for $120 \mathrm{~min}$.
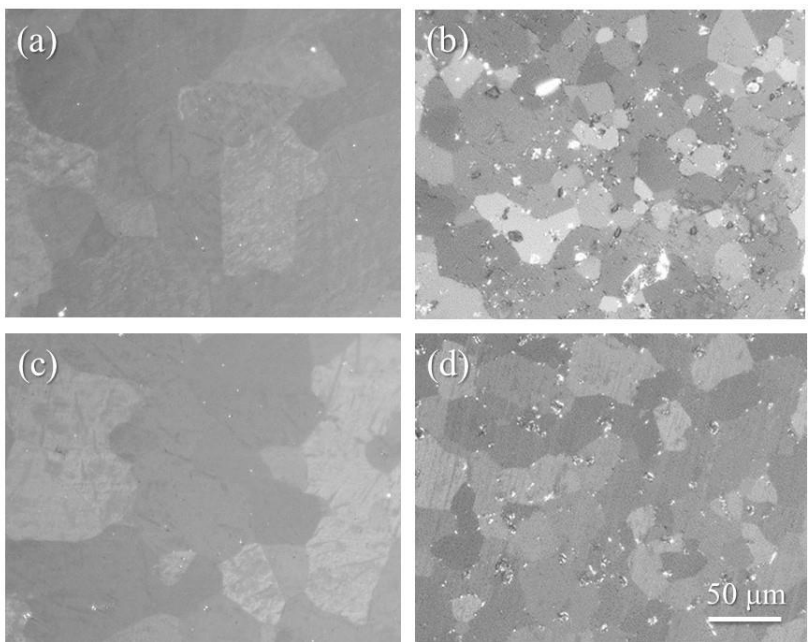

Fig. $6 \mathrm{OM}$ microstructures of (a) Ti sample heat treated at $1000{ }^{\circ} \mathrm{C}$ for $30 \mathrm{~min}$, (b) Ti- $0.3 \mathrm{vol} \% \mathrm{TiC}$ sample heat treated at $1000{ }^{\circ} \mathrm{C}$ for 30 min, (c) Ti sample heat treated at $1000{ }^{\circ} \mathrm{C}$ for $120 \mathrm{~min}$, and (d) Ti- $0.3 \mathrm{vol} \% \mathrm{TiC}$ sample heat treated at $1000{ }^{\circ} \mathrm{C}$ for $120 \mathrm{~min}$.

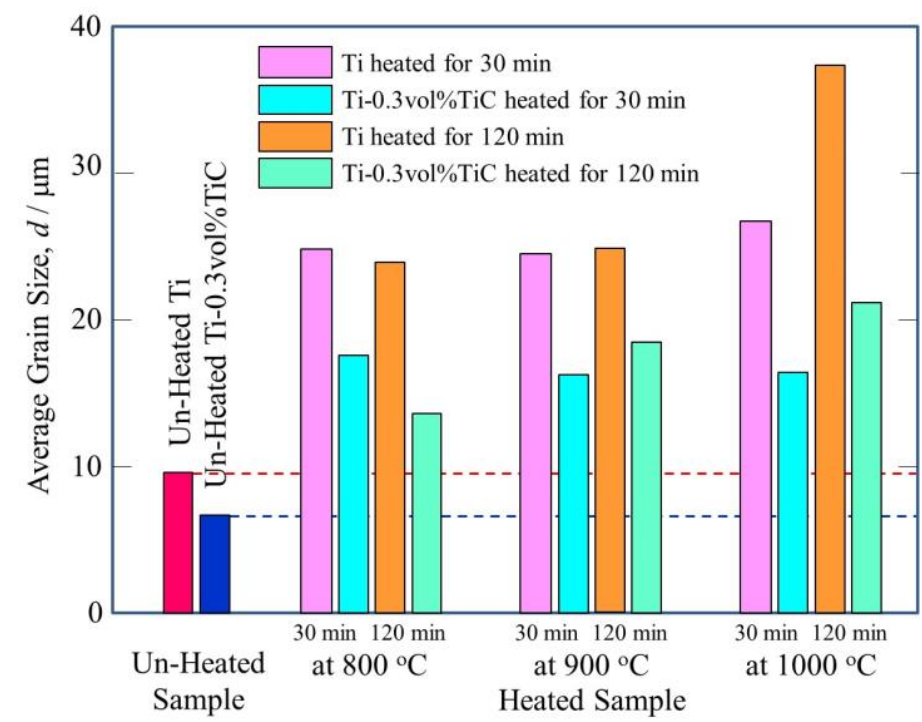

Fig. 7 The average grain size of the Ti samples and Ti-0.3vol\% TiC samples before and after the heat treatment. 


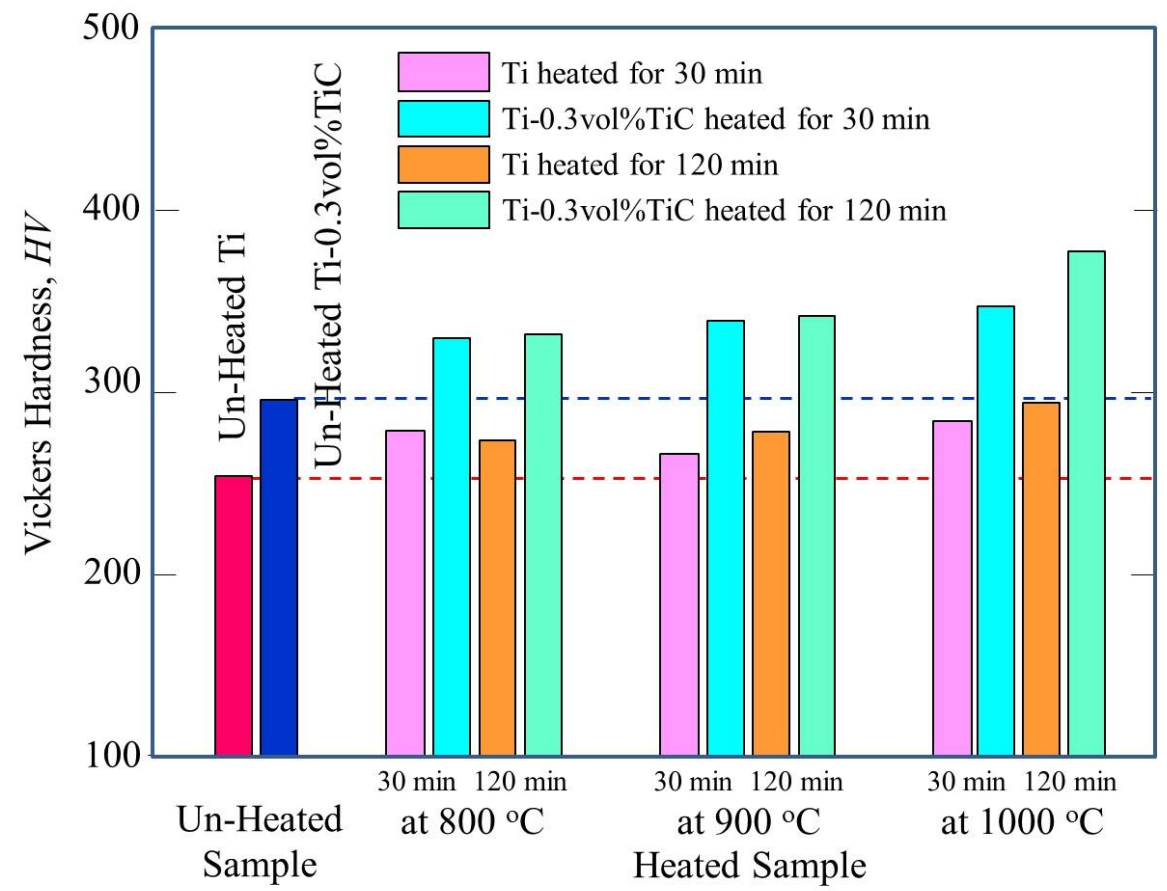

Fig. 8 Comparison of micro-Vickers hardness values for Ti and Ti-0.3vol\% TiC samples before and after the heat treatment.

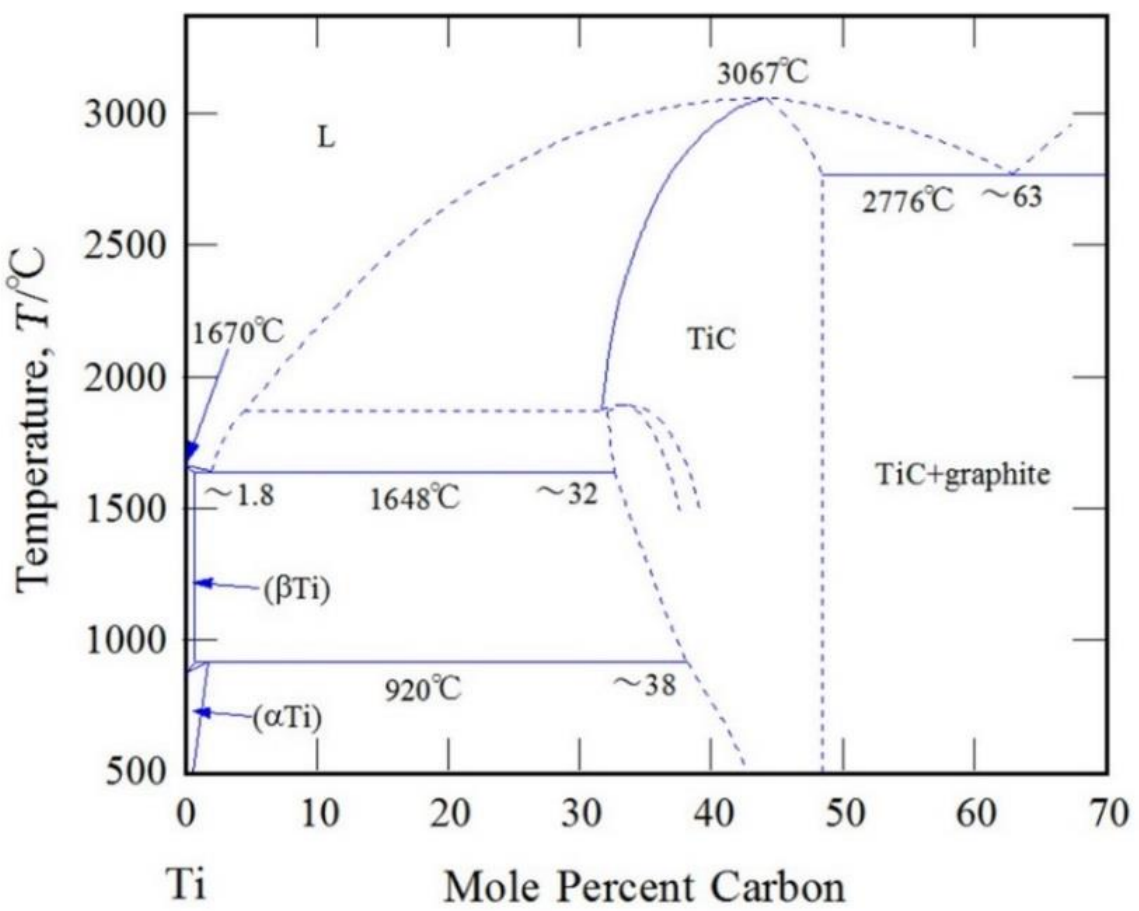

Fig. 9 Ti-C phase diagram (Redrawn from Ref. 12: T. B. Massalski, Editor-in-Chief: Binary Alloy Phase Diagrams, Second Edition Plus Updates on CD-ROM Version 1.0, ASM International, Materials Park, OH, (1996).). 